\title{
Comparative Analysis of Urdu and English Texts of "Subh-e-Azadi" by Faiz Ahmed
}

\author{
Faiz \\ * Liaqat Ali Mohsin, Assistant Professor \\ ** Sadia Asif, Assistant Professor (Corresponding Author) \\ *** Muhammad Imran Afzal, Senior Subject Specialist
}

\begin{abstract}
The translation of a poetic work is difficult because it needs to transfer poetic strategies, rhyme, and rhythm, and complex themes. Therefore, the translation lacks many structural and thematic features of the source text. The comparative translational analysis of a poem explores all these features and evaluates the translation in comparison to the source language (SL. The present study is the comparative analysis of Urdu text and English translated text of a milestone of "Subh-e-Azadi" by Faiz Ahmed Faiz, translated by Agha Shahid with the title "Dawn of Freedom" under the domain of Peter Newmark's model of translation. The poem was written in the backdrop of the creation of Pakistan with the dominant theme of lack of accomplishment of the promised dawn of equality, justice, and freedom. This article is a comprehensive account of the comparative analysis of both texts of the poem about strategies and procedures of translation, thematic and structural variations, translation shifts or transpositions, transference of meanings, and semantic variations.
\end{abstract}

Keywords: Comparative Analysis, Translation, Transposition, Transference, Independence Introduction

The critical analysis of a poem is an uphill task being embedded themes, rhyme and rhythm, metaphorical language, subject matters, subtleties of style, and culturally specific references. Thus, the translation of a poem loses many features that beautify it. (Bassnet, 1981) As it is well known saying by Robert Frost, "Poetry is what gets lost in translation." The poetic form entails the feelings and emotions related to themes of love, admiration, friendship, history, myth, fantasy, faith, etc which are so complicated and subjective that they can't be encompassed in the framework of translation to another language. The poets use their own experiences as well as fantasized ones that have a wide variety of subjects and intricacies. (Raffel, 1988)

The present study is a translation analysis of the poem "Subh-e-Azadi" by a famous Pakistani poet, Faiz Ahmed Faiz, translated by Agha Shahid as "Dawn of Freedom". Agha Shahid was born in New Delhi in 1949 and later brought up in Kashmir in a renowned and educated family. He died in 2001 but his works are still alive, and they manifest his omnipresence in his milestone achievements of poetic creation and translation of Faiz Ahmed Faiz. This poem was written in the backdrop of the creation of Pakistan to project the shattered visage of a newly born state. The poem carrying a sad undertone is ironic with underlying criticism on the leaders who got Pakistan to give equality, freedom, justice, and abolition of poverty and injustice for which Faiz had raised his voice over time and had been sentenced to imprisonment for the same. Thus, the poem is a message for continuous struggle to get the dawn of freedom longed for. (Hussain, 1989).

The common features of Faiz' poetry are the blend of nationalism/realism and romance, progressive ideas, figurative language, socialist philosophy, and optimism. (Dryland, 1993). His style is difficult for common readers because of ornate diction and the blend of Persian and Arabic vocabulary. Being a progressive poet, his poetry is about the working and labor class against the despotism of Ayub Khan and Zia ul Haq, two military rulers. His poetry is symbolic with common metaphors like "zulmat and noor", "shab", "Sahar", "Sahil", "hussan", "haseena", "manzlo gam", "ahle dard", "hijran", "chiraag" etc. (Hussain, 1989). 


\section{Purpose of Study}

This research is based on the investigation to find out the techniques of translation used by Agha Shahid. The analysis further involves the variation of themes, structures, and meanings in the translated text (TL) during the process of translation. It explores the variations and shifts of grammatical structures in TL (Asif et.al, 2018).

\section{Research Questions}

This research is trying to explore the following research questions:

a) What are the techniques of translation used by the translator?

b) What are semantic, structural, and thematic variations of source language (SL) and translated text (TL)?

\section{Significance of the Study}

This research is intended to find out the miscommunication of peculiar themes and ideas of Faiz Ahmed Faiz for the purpose to make the English readers get aware of them to get the ultimate function of aesthetic pleasure lying in the literary works. In this way, the readership of Faiz will enhance with acquaintance with his peculiar ideas and themes. It will also give an insight into the themes of freedom, equality, justice, freedom of speech, raising voice against atrocity, advocacy of the rights of the working-class which are present in the works of Faiz Ahmed. He has become the voice of the oppressed class with many historic poems like "Hum be dekhain gye" and "Bol kay lab azaad hoye". Thus, the study will increase the scope of the poem, arousing the democratic values which are the essence of the modern enlightened world. Moreover, Faiz is a renowned poet with Lenin Award (equivalent to the Nobel Prize) due to which his acquaintance with the present generation is supposed to result from this study.

\section{Delimitations}

This study is limited to the analysis of "Dawn of Freedom" by Agha Shahid in the light of Peter Newmark Model of translation. Moreover, the study is limited to Faiz Ahmed Faiz's only poem of "Subh-e-Azadi" which is related to the theme of independence.

\section{Literature Review}

The world has become a global village in which people of the world are just like a family with intensive needs of translation studies to promote mutual communication and exchange of ideas and feelings (Bernacka, 2012). According to Bell (1991), translation is a process of translating and the product of translation. Bassnett (1980) emphasizes the similarity of TL and SL and possibly close structures without compromising the correctness of TL. Eugene Nida (1969) gave the idea of dynamic equivalence or functional equivalence of the receptor language sentences which are the closest to the source language not only in meanings but also in style. Newmark (1981) emphasized the text and its analysis on multiple levels with a special focus of context.

Thus it can be concluded that the purpose of translation is to convey the intended meanings of the writer for which he/she has to be aware of the context, the intention of the text, attitude, text styles, and readership (Newmark, 1988). Two major books in this regard are: "Approaches to Translation (1981)" and "A Textbook of Translation (1988)". In the former book, he has projected the communicative aspect of translation, dividing translation into two categories named "semantic translation" and "communicative translation" while in the latter, he has categorized theories, principles, methods, and culture in translation. The translation methods are associated with all the texts while translation procedures are concerned with the sentences and smaller units of the language. His idea of translation is based on four major entities like culture, language, the writer, and the reader. Keeping in view the focus of the translation, he divides it into eight types: Literal translation, Wordfor-word translation, Faithful translation, Semantic translation, Adaptation, Idiomatic translation, free translation, and Communicative translation.

Newmark goes further to describe the levels of translation as the textual level, the referential level, the cohesive level, and the level of naturalness. While analyzing text, he mentions different language functions like expressive, informative, evocative, aesthetic, phatic, and metalingual. The procedures for the translation by Peter Newmark are: Transference, Cultural equivalence, Naturalization, Functional equivalence, Descriptive equivalence, Shift, Synonymy, Modulation, Compensation, Reduction, Explanation, and Paraphrase.

Baker (1992) finds the variation of grammatical structures and the resultant hindrance to translation for which the translator must use the procedures of addition and omission of certain 
information in TL. Thus he/she should have the competence of grammatical devices of both languages. Further, she gives eight different strategies adopted by translators: 1) the use of more general words. 2) Use of neutral/less expressive word. 3) Use of cultural substitution. 4) Use of loan words/loan words with explanation. 5) Use of paraphrase by related words. 6) Use of unrelated words. 7) Translation by omission. 8) Translation by illustration.

Chesterman (1997) gives the idea of local translation with semantic, syntactic, and pragmatic strategies with further subcategories. The syntactic strategies include: "literal translation, loan translation transposition, unit shift, paraphrase structure change, clause structure change, sentence structure change, cohesion change, level shift and scheme shift." The semantic categories are: "synonymy, antonymy, hyponymy, converses, trope change, abstraction change, distribution change, emphasis change, and paraphrase strategy." The pragmatic strategies include: "cultural filtering, explicitness change, information change, interpersonal change, speech act, visibility change, coherence change, partial translation and trans-editing." Venuti (2001) states two main methods of translation: direct/literal and oblique. The oblique translation is subdivided into: "borrowing, calque, literal translation, transposition, modulation, equivalence, and adaptation."

The present study follows the model of Peter Newmark (1988) with broad terms of, norms, culture, setting, tradition, writership, readership, and translatorship in both the languages.

\section{Methodology}

The present research is descriptive and qualitative owing to poetic analysis. It is the comparative and contrastive analysis of both versions Urdu text and English one. The theoretical framework used for the study is Peter Newmark Model of translation (1988) to determine the type of translation as well as the processes used by the translator. The model is concerned with methods applied by a translator, depending upon the focus either on SL or TL. The data used for this study is the poems by Faiz Ahmed Faiz with a sample restricted to "Subh-e-e-Azadi" because of the superb theme of freedom and other values like justice, equality, and abolition of poverty and oppression.

\section{Data Collection and Analysis}

The data of the research consists of Urdu and English text of "Subh-e-Azadi" by Faiz Ahmed Faiz and Agha Shahid, respectively. The analysis of the translated poem includes structural, semantic, and thematic variations along with the translation techniques used by the translator.

\section{Structural Variations and Shifts}

According to Newmark, there are four types of shifts used by the translator. The translator has also used various types of transposition or shifts.

1. "Ye" in the first line is single but it is translated to "these"

2. "Daag daag" inline 1 is an idiomatic emphasis but it has no equivalence in English. Moreover, it is a noun making compounding with "Ujala" but in the TL, it is translated as "tarnished" which is an adjective. There is a category shift.

3. "Ye WO Sahar to Nahin" inline 2 and 3 has been used two times, but in TL it is used only one time, "This is not that Dawn". This omission is because of a lack of grammatical structures in TL which has no use for two times.

4. "Intizaar" is a noun but it has been translated as "ravished with freedom" which is a participle phrase. There is a shift of category.

5. "Yar" inline 4 is a noun in SL but in TL, it has been replaced with a pronoun, "we" which is another category shift.

6. "Jis ki arzoo lay kar" is an infinitive phrase inline 3, but its translation is "in sheer longing" which is a prepositional phrase. It is a unit/grammatical shift.

7. "Mil Jaye gi Kahin Na Kahin" in line 4 of SL shows passivity while the translator has put action into it by changing the shift of emphasis "we would find it" in line no 5.

8. "Kahin to ho ga" is a phrase with future meanings but it has been translated as "we had no doubt" which is a clause with past connotation. It is an example of a unit/structural shift.

9. Inline no 6, "Sahil" is the theme of "Kahin to ho ga" but in TL, the theme is "night's vagrant wave" and "the shore" has been made the theme of the prepositional phrase. There is a shift of focus.

10. "Kahin" in line no 7 is "its port" which is another shift of category. SL has a pronoun while TL has a noun phrase. 
11. The line no 8 and 9 make an assertive sentence with historical allusion of the freedom movement and its troubles. But the TL starts with the vocative noun "Friends" which shows the transposition from declarative to vocative.

12. Inline 11, two verbs of "pukaarti rahin" and "bulati rahin" have been translated as "enticing us to stay" and "cried out" in line no 9 and 10, respectively. The former is present participle which is a shift of category. SL has the coordination of both verbs, but TL has the main verb of "cried out" with the present participle "enticing us" as an adverb.

13. In lines no 12-14, four "marakab e azafi" like "rukh e Sahar ki lagan", "haseenan e nor ka daman", "subak subak Tamanna" and "Dabi Dabi thakan" are translated as "beckoning dawn", "her muslins of transparent light", "Our blood was young" and "what could hold us back?" respectively. There are various examples of the shift in TL in all examples. In the first one, there is no compounding as it is in SL while the second one has the expansion of the SL structure. In the fourth example, there is a shift of grammatical structure as it is assertive in SL but interrogative in TL.'

14. Inline no 15 , the SL is in the declarative mood while there is a significant shift of grammatical structure in TL in which there is an imperative mood.

15. "Our feet are now one with their goal" is the translation of "wisal e manlo gaam". It is evident that SL has a compound noun (murakab e azafi) but TL has a clause as translation. There is a shift of grammatical structure in it.

16. In lines no 17 and 18 , there is a structural variation or shift. SL in line no 17 is in present perfect tense while its translation is in present indefinite. SL shows completion of deterioration while TL is the present condition. Inline no 18, two noun phrases (murakb e azafi) have been translated as "Indeed, we must confess only to bliss;" and "we must surrender any utterance for the Beloved -all yearning is outlawed" which are clauses. This is an example of a structural shift from the source language. The TL is the modulation of assertive to modal sentence with "must".

17. Theme and rhyme have been changed in line 23 of TL. In the SL, "Chirag" is the theme of the sentence, but it is rhyme (object) of installed. This is a shift of focus with passivity.

18. Line no 23 has a shift of verb in TL line no 25 with "girani" which is a noun that has been modulated to "weighs down" as a verb. The present perfect tense of SL has been changed into the present simple.

19. Inline no 26 of TL, there is another example of a shift in which the imperative mood of SL "chalay Chalo" has been changed into subjunctive mood "must search...."

\section{Semantic and Thematic Variation}

Newmark (1988) gives the idea of context, readership with cultural norms and traditions in his historic model of translation. The ideas of context and culture are related to thematic and semantic aspects.

1. "Ujala" inline 1 is metaphorical and means the light of freedom but in TL, it is translated as "rays" which is deviant in meaning as well as lacking in metaphorical meanings.

2. "Night-smudged light" has no equivalence with "shab gazeeda Sahar" because the latter has many historical and contextual meanings of the historic creation of Pakistan with painful massacre and sacrifices. Moreover, "Night-smudged light" has no such compound in TL according to Oxford Dictionary. It shows an attempt to have translation at a literal level, ignoring the themes of Faiz's poetry.

3. "Sahar" inline 1 and 2 has two different translations "light" and "dawn" even though it has similar connotations in SL. Thus, it results in a significant variation of meanings.

4. "Akhri manzil" has become "a final haven" in TL which lacks the meanings of progressive ideas of Faiz Ahmed Faiz due to which his poetry is replete with dynamic images and themes.

5. Inline no 7, "Safeena e dil e Gham" has been translated as "heart rocked with sorrow" which has variation of meaning and theme of movement of the struggle for freedom, justice, and equality according to the poet. Moreover, "Shab e susat moaj" is a slow-moving night towards the real dawn of freedom while in TL, "Night vagrant wave" is homeless straying without any direction or destination. It is the sheer difference of meanings and themes.

6. "Jawan lahoo" in line no 8 is the metaphor of passion and youth but "our blood" in TL is mere literal in meanings. Moreover, the idiomatic phrase of "daman per kitney hath paray" in 
line no 9 has been translated as "hands tugged at our sleeves" which loses the charm of historical and metaphorical meanings.

7. In TL, the allusion to the Greek Mythology of Odyssey when he was tempted by bare goddesses called "Sirens" is obscure for common readers of Faiz Ahmed Faiz. Moreover, the common symbols of "dayar e hussan", "besabar khawab gahen" and "bahain, Badan" are used for the temptation of beauty. But they have lost in the allusions of Sirens in TL.

8. Inline 12, the translation of "BHT azez the" as "our eyes fixed on that" while the translation of "rukh e Sahar ki lagan" as "beckoning dawn" has no metaphorical equivalence in TL. Inline no 13 , "bht qareen tha" is "forever vivid" who is meaning is totally out of context on which the Newmark's model is based. The "muraqab" of "haseenan e nor ka Daman" has been translated as "in her muslins of transparent light", which shows a type of garment rather than a person. Besides this, the line no 14 is replete with variation of meanings and themes. "Subak subak the Tamanna" is a passionate feeling for the new land of Pakistan while "Dabi Dabi the thakan" is the tiredness after a long struggle to achieve Pakistan. In the translated text, there is no contextual consideration by the translator.

9. "Ahle dastoor" are the men of letters in Urdu poetry, the sensitive people who feel the pain of others. But in TL, it has been translated as "our leaders" which does not convey the intended meanings of the poet. Inline no 18, the poet describes the traits of present men of letters that they avoid pangs and pain rather they consider it right to enjoy the bliss of a comfortable and luxurious life. Line no 19 and 20 in TL are totally out of context of the SL without any reference to the historical allusion.

10. The line no 21 of TL, there is no translation of metaphorical expressions of line no 19 and 20 of the SL. It makes the variation of theme. The metaphorical expressions of "Jigar ki aag, Nazar ki omang and dil ki Jalan" reflect the strong passion of freedom which was not affected by "chara e hjran" of line 20. It was indomitable will and insurmountable passion for freedom which could not be shattered with troubles and challenges.

11. "Nigar" in line 21 of SL is the metaphor for beloved, which has no translation in the TL. The symbols of "nighar e suba" and "chirage SAR e rah" are very significant, pregnant with meanings. The former is the symbol of ray of hope while the latter is the newly born country surrounded by challenges.

12. The themes in lines 23-25 are about the creation of Pakistan and the progressive movement with an optimistic struggle towards a bright future in the form of a beloved country. All these contextual ideas are missing in TL.

\section{Translation Techniques and Strategies}

Newmark (1988) elaborates on different procedures to analyze any translation. These procedures are the techniques and methods used by the translator.

1. Line no 1 is a literal translation with nearest equivalents but they are out of the context of the poem which carries the theme of partition and promised the creation of a dreamland of Pakistan.

2. The translation of lines $2-5$ holds free translation without careful of contents, context, and manner of SL. The order and arrangement of SL has been toppled up to create a new compact whole.

3. "Ye WO Sahar to nahin" has been used two times in SL but translated only one time in TL. It shows the strategy of deletion to show faithfulness to TL as such sort of repetition is not common in TL.

4. "So sure that" in line no 4 in TL has no equivalent in SL which shows that the translator has made the strategy of addition to stress the theme of hope.

5. Inline no 6, there is a deletion of "safeena" in TL which has special semantic connotations in Faiz' poetry.

6. Inline no 6 and 7, the translator has translated two compounds called "morakab e azafi" named "shab e susat moaj" and "safeena e Gham e dil" with literal translation, ignoring the thematic and semantic context.

7. Both lines no 8 and 9 in TL are literal translation of verses with complete ignorance of thematic and semantic meanings. There is the addition of "friends" and the deletion of "jawan" in TL. 
8. Line no 10 is free translation without consideration for content, form, and manner with the substitution of "Sirens" for the whole line. Inline no 11, "bare" is added to "bodies" which is an addition to the translation of "badan".

9. In the lines no 12, "rukh e Sahar ki lagan" has been translated with the use of reduction. In SL, there are four words while in TL, there are two only. In the line no 13 and 14, one, there is expansion of SL. There is free translation blended with a literal one with subsiding the thematic aspects of SL.

10. "Suna ha ho be Chuka" in line no 15 and 16 has been translated only one time in TL which is omission of repeated structure. The translation of "wisal e manlo gaam" in line no 16 is "our feet are now one with their goal" which is an example of idiomatic translation with paraphrase in TL because of having no equivalence.

11. Inline 19, "Jigar ki aag", "Nazar ki oman" and "dil ki Jalan" have been translated as "the heart, the eye, the yet deeper heart" respectively in the line no 21 which shows the strategy of reduction. All the compounds, idiomatic expressions of SL are Noun phrases (Marakab e azafi) but the TL are mere nouns. This also reflects the idiomatic translation and free translation. Couplets have been used by the translator while translating, using the addition of "but, the yet" and "the" with all nouns which carry no meanings in SL.

12. The TL in line no 22, there is free translation of line 20 in SL, without translating "chara e hijran", "Kuch asar" and "Kisi per". Moreover, the translator has used "still ablaze for" and "their turmoil shines" are additions made to TL which further translate free one.

13. The translation of line no 21-22 in SL is not in the same sequence of verses. Their sequence has been changed. It shows that there is literal and free translation.

14. The metaphorical expression of "nijat e deed o dil" in the line no 24 of the SL is un-translated Conclusion in TL. The translation of line 24 of SL in line no 26 is paraphrased and self-translation.

From the above discussion, it can be concluded that the translation of "Subh-e-Azadi" by Agha Shahid has many semantic, structural, and thematic variations from the SL. The background theme of the poem (freedom) has been often ignored in TL. Thus, the idea of context in Peter Newmark's model is no more considered by the translator in this instance. Moreover, the metaphorical symbols of "Sahar, shab, manzil, Sahil, moaj, safena, lahoo, hussan, hassenan e nor, zulmat, nor, manzl o gaam, wasal and hijar" are translated literally without considering the contextual relationship to the central and cultural themes. It shows the ignorance of the translator from pure Urdu poetry trends. As a result, the translator has translated most verses using literal, idiomatic, and free translation types. The idioms have been paraphrased in TL. In his translation, he has used many strategies as proposed by Peter Newmark, like deletion, omission, modulation, couplets, paraphrase, expansion, and synonymy. The translator has also used various types of shift exemplified as structural shift, class shift, unit shift, word form shift, and focus shift. Besides, the figures of speech have not been translated in TL and because of that, the target text has resulted in the loss of themes and contextual meanings.

\section{References}

Asif, S., Zafar, S., Bhatti, Z., \& Naeem, T. (2018). A comparative analysis between English and Urdu translated versions of Jalaluddin Rumi's Poem. Hamdard Islamicus, 14 (1), 268-281

Baker, M. (1992). In other words: A coursebook on translation. Routledge.

Bassnet, S. (1980). Translation studies. Methuen.

Bassnet, S., \& Lefevere, A. (1990). Translation. History and culture. Pinter.

Bassnett, S. (2005). Translation studies (3rd Ed.). Routledge Taylor and Francis Group.

Bell, R. T. (1991). Translation and translating: Theory and practice. Longman.

Bernacka, A. (2012). The Importance of translation studies for development education, in policy \& practice. A Development Education Review, 14, 113-118.

Catford, J.C. (2000). Translation shifts. In L. Venuti (Ed.). The translation studies reader (pp. 141147). Routledge.

Chesterman, A. (1997). Memes of Translation: The spread of ideas in translation theory. John Benjamins.

Dryland, E. (1993). Faiz Ahmed Faiz: Urdu poet of social realism. Vanguard Books (Pvt) Ltd. Print.

Hussain, I. (1989). An introduction to the poetry of Faiz Ahmed Faiz. Vanguard Books (Pvt) Ltd. Print. 
Nida, E.A. (1964). Towards a science of translating. E.J. Brill.

Nida E.A., \& Charles R.T. (1982). The theory and practice of translation. E. J. Bill.

Newmark, P. (1981). Approaches to translation. Pergamon Press.

Newmark, P. (1988). A textbook of translation. Prentice-Hall.

Raffel, B. (1988). The art of translating poetry. Penn State Press.

Siddiqui, Dr. M. A. (2011). Faiz Ahmad Faiz: Dard aur darmaan ka shair. Peace Publications.

Venuti, L. (2000). The translation studies reader. Routledge. 